\title{
PENJABARAN GOOD CORPORATE GOVERNANCE (GCG) DALAM PENGADAAN BARANG DAN JASA PADA PLN BALI
}

\author{
Oleh :
}

\section{Luh Putu Dwi Suarini'}

\begin{abstract}
Research in connection with the theme is "Implementation of Good Corporate Governance (GCG) in Procurement at PLN Bali”. The problems are researched the translation of good corporate governace forms in the procurement of goods and services at PLN Bali and the form of the procurement of goods and services at PLN Bali.

This research includes the category of empirical legal research, legal research is a empirical means reviewing the practical reality in daily life - today. The nature of the research is descriptive research that has a goal to paint a picture of something in the area and at a certain moment. Furthermore, the technique used is to study documents, interviews, NonProbability Sampling, purposive sampling.

Procurement of goods or services in PLN involves many parties, the employees who were appointed to take care of such procurement and future providers of goods and services. In this relationship unfair business competition or the price is too high or low in supply. However, the existence of e-procurement and the correct procedures in the procurement of goods and services as well as the concept of GCG which also animates the principles of procurement of goods and services. Procedures in the procurement of goods and services as well as the principles of GCG, the procurement in PLN can be carried out transparently, responsibly, independently, fairly and equitably.
\end{abstract}

\section{Keynote : Good Corporate Governance, PLN, Procurement of goods and services}

\section{Pendahuluan}

\subsection{Latar Belakang Masalah}

Dalam kehidupan sehari - hari, masyarakat di Indonesia tidak pernah lepas dari penggunaan listrik. Di Indonesia, satu satunya BUMN yang bergerak dalam bidang ketenagalistrikan ialah PLN. PLN memiliki slogan PLN Bersih, No Suap, No Korupsi. Dalam hal tindakan dari slogan PLN tersebut, perusahaanyangberbentukPerseroanterbatas ini dibantu oleh Transparency International

Mahasiswa Magister(S2)Ilmu Hukum Universitas Udayan,Denpasar,Bali,Alamat: Jalan Sedap Malam III No.9, Denpasar,Email:wi.ubligh@ gmail.com
Indonesia (TII) untuk menerapkan Good Corporate Governance (GCG) yang fokus pada upaya pemberantasan korupsi dalam tubuh PLN khususnya sektor pengadaan barang atau jasa serta pelayanan publik. PLN sebagai organisasi usaha yang mengejar profit pasti sangat memperhatikan efisiensi dan efektivitas sehingga dibutuhkan Good Corporate Governance dalam perseroan. ${ }^{2}$ Beberapa tahun terakhir, GCG sangat populer terkait dengan perusahaan - perusahaan yang ada di Indonesia. Perusahaan merupakan sebuah institusi bagi sebagian besar dari

\footnotetext{
Fahri Hamzah, 2012, Negara,BUMN, dan
} Kesejahteraan Rakyat, Faham Indonesia, hlm.99. 
umat manusia untuk dapat memenuhi kebutuhan pokoknya. ${ }^{3}$ Forum For Corporate Governance in Indonesia (FCGI) mendefinisikan corporate governance ialah seperangkat peraturan - peraturan yang menetapkan adanya hubungan di antara para pemegang saham, pengurus, pihak kreditur, pemerintah dan karyawan juga dengan pemegang kepentingan intern dan ekstern lainnya berkaitan dengan hak serta kewajiban mereka, atau dengan kata lain sistem yang mampu mengarahkan serta mengendalikan suatu Perseroan. ${ }^{4}$

Definisi dari OECD (KelompokNegara Maju) dan Komite Cadburry menyebutkan bahwa $C G$ sebagai suatu sistem yang terdiri dari proses pengelolaan dan proses pengawasan terhadap pengelolaan. ${ }^{5}$

Prinsip-Prinsip dalam Good Corporate Governance (GCG) yang harus diterapkan PLN selaku BUMN dalam kegiatannya sebagaimana dimaksud dalam Pasal 3 PER-01/MBU/2011 yang dikeluarkan oleh Menteri Negara BUMN tentang Penerapan Tata Kelola Perusahaan yang Baik (Good Corporate Governance) Pada Badan Usaha Milik Negara, yaitu terdiri atas transparansi (transparency), akuntabilitas (accountability), kemandirian (independency), pertanggungjawaban (responsibility), seperangkat kewajaran (fairness).

Djokosantoso Moeljono, 2005, Good Corporate Culture sebagai inti dari Good Corporate Governance, PT Elex Media Komputindo, Jakarta, hlm.75.

4 Misahardi Wilamarta, 2007, Penerapan Prinsip - Prinsip Good Corporate Governance dalam Perseroan Terbatas, Center for Education and Legal Studies, Jakarta, hlm.7.

5 Wahyu Kurniawan, 2012, Corporate Governance Dalam Aspek Hukum Perusahaan, PT Pustaka Utama Grafiti, Jakarta, hlm.22.
Sektor pengadaan barang atau jasa melibatkan beberapa pihak sehingga diperlukan etika, norma, dan prinsip pengadaan barang dan juga jasa untuk dapat mengatur atau dijadikan dasar penetapan kebijakan pengadaan barang serta jasa. Pengadaan barang atau jasa secara elektronik tidakhanyadiharapkanmampumeningkatkan efisiensi dan transparansi, namunjuga sebagai penunjang pelaksanaan prinsip-prinsip, kemandirian, profesionalisme, akuntabilitas, dan pertanggungjawaban serta kewajaran atau yang dikenal dengan prinsip-prinsip GCG sebagaimana diatur dalam Pasal 5 ayat (3) Undang-undang Nomor 19/2003 tentang Badan Usaha Milik Negara (BUMN) bahwa dalam melaksanakan tugasnya, anggota Direksi haruslah mematuhi anggaran dasar dari BUMN dan peraturan perundangundangan serta wajib melaksanakan prinsip-prinsip profesionalisme, efisiensi, transparansi, kemandirian, akuntabilitas, pertanggungjawaban, serta kewajaran. Dari banyaknya jumlah proses pengadaan barang dan pengadaan jasa sangat rentan untuk dimanfaatkan sebagai sarana korupsi karena nilai dari pengadaan barang dan pengadaan jasa dapat dikatakan dengan nilai rupiah yang tidak sedikit. Pengadaan barang dan jasa pada BUMN tidak tunduk pada Peraturan Presiden No.54 tahun 2010 tentang Pengadaan Barang/Jasa Pemerintah melainkan tunduk pada peraturan yang lebih spesifik untuk BUMN yaitu Peraturan Menteri BUMN No.05/MBU/2008 tentang Pedoman Umum Pengadaan Barang dan Jasa Badan Usaha Milik Negara yang memberikan kewenangan pada tiap-tiap BUMN untuk mengatur pengadaan barang dan jasanya melalui ketentuan perusahaan. 
Hal ini juga berdasarkan pada, modal dari suatu BUMN yang didapat dari kekayaan pada Negara yang sengaja dipisahkan dari modal dasar berupa saham yang berjumlah minimal $51 \%$. Pengertian dipisahkan ini ialah bahwa modal BUMN yang disetor Negara atau daerah adalah kekayaan negara atau daerah yang dipisahkan dari APBN/APBD, dan pengelolaannya diserahkan kepada manajemen BUMN sebagai suatu entitas hukum yang terpisah. ${ }^{6}$ Pada pelaksanaannya dalam pengadaan barang dan jasa BUMN berlakulah asas lex specialis derogate lex generalis dimana peraturan yang digunakan ialah peraturan yang lebih khusus yaitu, Peraturan Menteri BUMN No.05/MBU/2008 mengenai Pedoman Umum Pengadaan Barang dan Jasa Badan Usaha Milik Negara dan mengenyampingkan Peraturan Presiden No.54 tahun 2010 tentang Pengadaan Barang/Jasa Pemerintah. Sehingga sangat menarik dilakukan penelitian.

\subsection{Perumusan Masalah}

1. Bagaimanakah bentuk penjabaran $G C G$ dalam pengadaan barang dan jasa pada PLN Bali ?

2. Apa saja yang menjadi kendala dan pemecahanmasalah dalampelaksanaan pengadaan barang dan jasa pada PLN Bali?

\subsection{Tujuan Penelitian}

Dalam penelitian yang dilaksanakan ini untuk mengetahui bentuk penjabaran dari $G C G$ dalam pengadaan barang serta jasa pada PLN Bali dan untuk menganalisis kendalakenda yang dihadapi serta solusi dari kendala -kendala tersebut dalam pengadaan barang

Marisi P. Purba, 2014, Pengadaan Barang dan Jasa $B U M N$, Graha Ilmu, Yogyakarta, hlm.11. serta jasa khususnya pengadaan barang serta jasa pada PLN Bali.

\section{Metode Penelitian}

Pada penelitian ini digunakan metode penelitian hukum empiris untuk meneliti yaitu pemecahan masalah yang ada dalam kehidupan sehari - hari melalui cara mengkaji dari peraturan yang berlaku, teori hukum, serta norma hukum yang berdasarkan realita yang ada. Pada penelitian ini bersifat deskriptif dengan tujuan untuk memberikan gambaran tentang hal tertentu pada suatu daerah. ${ }^{7}$ Lokasi penelitian yang digunakan oleh penulis ialah pada PLN Bali. Data yang diteliti dalam penelitian ini yaitu data primer serta data sekunder. Teknik pengumpulan data yang penulis gunakan ialah teknik studi dokumen serta teknik wawancara. Untuk teknik penentuan sampel dalam penelitian ini ialah teknik Non Probability Sampling khususnya teknik purposive sampling. Dalam pengolahan dan analisis data untuk penelitian ini dilakukan dengan cara kualitatif.

\section{Pembahasan}

\subsection{Penjabaran Good Corporate} Governance(GCG)dalampengadaan barang serta jasa pada PLN Bali

Dalam pengadaan barang serta jasa pada PLN Bali dapat dilihat pada beberapa tindakan yang diawali dengan sejalannya prinsip pengadaan barang sertajasa pada PLN Bali dengan prinsip yang terkandung dalam GCG, yaitu: Transparency, Accountability, Responsibility, Independency, Fairness. Prinsip-prinsip pengadaan barang serta

Bambang Waluyo. 2008, Penelitian Hukum Dalam Praktek, Sinar Grafika, Jakarta,hlm.8. 
jasa tersebut ialah; Efisien, yaitu pengadaan barang atau pengadaan jasa harus diusahakan untuk mendapatkan hasil yang optimal dan terbaik dalam waktu yang cepat dengan menggunakan sumber daya seminimal mungkin secara wajar dan bukan hanya didasarkan pada harga terendah; Efektif, yaitu Pengadaan barang atau pengadaan jasa harus sesuai dengan kebutuhan yang telah ditetapkan serta mampu memberikan manfaatyangsebesar-besarnyasesuaidengan sasaran yang telah ditetapkan; Kompetitif, yaitu pengadaan barang atau pengadaan jasa harus terbuka bagi Penyedia barang atau penyedia jasa yang memenuhi persyaratan yang dilakukan melalui persaingan yang sehat diantara penyedia barang atau penyedia jasa yang setara dan memenuhi syarat atau kriteria tertentu berdasarkan ketentuan dan prosedur yang jelas dan transparan; Transparan, yaitu semua ketentuan dan informasi mengenai pengadaan barang atau jasa, termasuk syarat teknis administrasi pengadaan, tata cara evaluasi, hasil evaluasi, penetapan calon penyedia barang atau jasa, sifatnya terbuka bagi peserta penyedia barang atau jasa yang berminat; Adil dan wajar, yaitu memberikan perlakuan yang sama bagi semua calon penyedia barang atau jasa yang telah memenuhi syarat yang ditentukan; Akuntabel, yaitu harus mencapai sasaran serta dapat dipertanggungjawabkan sehingga menjauhkan dari potensi penyalahgunaan dan penyimpangan. Pengadaan barang serta jasa pada PLN Bali tidak lepas dari sistem elektronik yaitu E-procurement. Misi dari E-procurement ialah bagaimana proses pengadaan barang serta jasa di pemerintahan dan bagaimana caranya memanfaatkan teknologi informasi agar tidak membuang waktu dan biaya. ${ }^{8}$

Pengadaan barang dan jasa diawali denganperencanaan.Perencanaanmerupakan susunan langkah-langkah sistematik melalui upaya pemanfaatan sumber - sumber yang tersedia dengan memperhatikan segala keterbatasan guna mencapai tujuan secara efisien dan efektif. ${ }^{9}$ Kemudian dilanjutkan dengan proses pengadaan melalui beberapa metode. Dalam pengadaan barang dan jasa pada PLN Bali terdiri dari empat (4) metode, yakni :

a. Pengadaan langsung;

b. Penunjukkan Langsung;

c. Pelelangan Terbuka;

d. Pelelangan Terbatas

Untuk proses pengadaan barang dan juga jasa pada PLN Bali tersebut di atas dapat dilihat pada prosesnya yang menjabarkan tentang GCG yaitu :

a. Unsur Transparency ; dapat dilihat pada aplikasi pengadaan barang atau jasa yang mana memberikan informasi pengumuman rencana pengadaan barang/jasa kepada siapa pun termasuk kepada seluruh external user untuk mendapatkan perlakuan (informasi pengadaan barang/jasa, pengumuman hasil pengadaan barang/jasa) yang sama. Dalam pengadaan barang/ jasa pada PLN Bali, pengumuman pengadaan dilakukan melalui sistem E-Procurement ataupun melaui

Richardus Eko Indrajit, dkk, 2002, E-Government Strategi Pembangunan dan Pengembangan Sistem Pelayanan Publik Berbasis Teknologi, Andi, Yogyakarta, hlm.151.

9 Samsul Ramli dan Fahrurrazi, 2014, Swakelola Pengadaan Barang/Jasa Pemerintah, Visi Media Pustaka, Jakarta, hlm.5-6. 
pengumuman yang ditempelkan pada papan pengumuman pengadaan PLN.

b. Unsur Accountability ; dapat dilihat pada saat adanya proses pengadaan, dalam melakukan tender/lelang untuk mendapatkan harga yang terbaik Pejabat Pelaksana pengadaan melakukan negosiasi terhadap penyedia barang/jasa agar harga dapat disesuaikan dengan kualitas dari barang/jasa tersebut dan harga berada di bawah Harga Perkiraan Satuan (HPS). Kemudian proses pengadaan tersebut telah dipastikan sesuai dengan metode pengadaan barang/ jasa yang ada dalam SOP (Standar Operating Procedure) dan kebijakan perusahaan. SOP ialah sekumpulan manual pekerjaan yang mencerminkan langkah - langkah aktivitas, arus data dan personil yang mengerjakannya dalam suatu organisasi. ${ }^{10}$

c. Unsur Responsibility ; bentuknya dapat dilihat pada adanya pelatihan E-procurement. Seleksi berdasarkan E-procurement pada PLN Bali dengan persyaratanterukurmampumengurangi kontak langsung antara pengguna, penyedia serta Pejabat Pelaksana Pengadaan dan hasil dari pelaksanaan pengadaan melalui E- Procurement dapat dipertanggungjawabkan.

d. UnsurFairness; bentuknyadapatdilihat dalam membangun kerjasama dengan para penyedia barang/jasa, menyeleksi setiap kualifikasi sesuai persyaratan tanpa intervensi pihak ketiga sehingga

Hasbullah F. Sjawie, 2013, Direksi Perseroan Terbatas serta Pertanggungjawaban Pidana Korpoorasi, Citra Aditya Bakti, Bandung, hlm.112. dapat menjamin peluang yang sama kepada para penyedia barang/jasa untuk memenangkan lelang.

e. Unsur Independency ; yaitu tidak ada tekanan dari pihak manapun dalam menentukan pemenang penyedia barang serta jasa asalkan sudah sesuai dengan peraturan PLN yaitu sesuai dengan SK Direksi No. 620/2013, membuka kesempatan yang sama pada semua calon penyedia barang serta jasa untuk mengajukan penawaran tanpa adanya metode pemilihan langsung, dikarenakan metode pengadaan pemilihan langsung sudah tidak berlaku lagi di PLN.

\subsection{Kendala yang dihadapi serta Pemecahan Masalah dalam Pengadaan Barang/ Jasa pada PLN Bali}

Ada beberapa kendala yang dihadapi dalam proses pengadaan barang/jasa di PLN Bali. Kendala ini dihadapi oleh berbagai pihak, baik itu Penyedia barang/jasa ataupun Pejabat Perencana serta Pejabat Pelaksana pengadaan. Hasil wawancara dengan Bapak I Gede Ketut Anom mengemukakan kendala yang terjadi dalam proses Perencana Pengadaan Barang/ Jasa ialah; ${ }^{11}$

a. Untuk persyaratan calon penyedia barang/jasa, diwajibkan menggunakan laporan keuangan yang telah di audit, namun penyedia barang/jasa di Bali sangat jarang laporan keuangannya di audit sehingga hampir semua tidak memenuhi persyaratan untuk menjadi peserta.

\footnotetext{
11 Bapak I Gede Ketut Anom (Pejabat Perencana Pengadaan pada PLN Bali) wawancara dilakukan di Denpasar pada Jumat,8 Mei 2015)
} 
Pemecahan masalahnya ialah untuk menghindari pengadaan gagal yang akan menghabiskan waktu lebih banyak lagi dan untuk mewujudkan efisiensi serta efektivitas waktu dan biaya, maka saat aanjwizing (Penjelasan) dilakukan, dijelaskan bahwa adanya permakluman dari Pengguna bahwa calon penyedia barang dan jasa dapat menggunakan laporan keuangan yang belum di audit dan untuk pengadaan berikutnya diharapkan laporan keuangan perusahaan telah di audit.

b. Untuk penyusunan Daftar Penyedia Terseleksi (DPT) seperti yang disyaratkan dalam Ketentuan Pengadaan Barang/Jasa PT PLN yaitu SK Direksi No. 620 tahun 2013 tentang Pedoman Pelaksanaan Pengadaan Barang dan Jasa di lingkungan PT PLN (Persero) beserta perubahannya belum ada, diakrenakan adanya peralihan aturan dari SK Direksi sebelumnya yang belum mengatur DPT dan dibutuhkan waktu untuk membuat DPT. Pemecahan masalahnya ialah saat belum ada DPT digunakan sistem lelang terbuka agar proses kualifikasi calon penyedia barang/jasa lebih transparan dan dapat dikualifikasi lebih cermat.

Wawancara kedua ialah dengan Ketut Mindiawan, yang menuturkan beberapa kendala dalam pelaksanaan pengadaan barang/jasa pada PLN Bali ialah; ${ }^{12}$

a. Saat persediaan material di salah satu unit PLN Bali habis dan material

Ketut Mindiawan (Pejabat Pelaksana Pengadaan pada PLN Bali), wawancara dilakukan di Denpasar pada Jumat, 8 Mei 2015 tersebut harus segera diadakan untuk menghidari penumpukan antrian pelanggan sedangkan material tersebut menunggu justifikasi dari PLN Bali, dimana unit - unit yang membutuhkan material tersebut bersifat segera. Pemecahan masalah ini ialah unitunit ini diberikan kewenangan untuk memesan material tanpa justifikasi berlandaskan pada pengadaan darurat yang diatur dalam SK Direksi No.620 tahun 2013, didasarkan pada pemilik perusahaan yaitu pemegang saham yang diwakilkan oleh General Manager untuk tingkat Distribusi memberikan kekuasaan kepada Manajer untuk unit yang lebih kecil dimana ManajerManajer ini perpanjangan tangan untuk melayani pelanggan sehingga kewenangan yang diberikan adalah untuk memenuhi kebutuhan pelanggan seefektif mungkin dimana Manajer ini pelaksana yang dapat dipercaya untuk kepentingan umum dan stakeholder.

Wawancara ketiga dilakukan dengan I Gde Arie Widyantara Partha, dari penuturannya kendala yang dihadapi dalam perencanaan dan pelaksanaan pengadaan barang dan jasa di unit yang lebih kecil, khususnya dalam hal ini PLN Area Bali Selatan ialah; ${ }^{13}$

a. Dalam pengadaan barang/ jasa diharuskan membuat DPT seperti yang diatur dalam SK Direksi No 620 tahun 2013, namun DPT yang menjadi

\footnotetext{
13 I Gde Arie Widyantara Partha(Supervisor Pelaksana Pengadaan Area Bali Selatan), wawancara dilakukan di Denpasar pada Jumat, 8 Mei 2015.
} 
kewenangan PLN Bali (Kantor Induk) belum siap dikarenakan peralihan SK Direksi, sedangkan pengadaan barang/ jasa harus tetap berjalan. Pemecahan masalahnyaialah denganmenggunakan metode lelang umum prakualifikasi maupun pascakualifikasi, karena dengan metode ini segala persyaratan administrasi dan teknis diverifikasi.

b. Saat pengajuan penawaran dari para rekanan sering terjadi mengajukan nilai penawaran di atas Harga Perkiraan Sendiri(HPS). Pemecahan masalahnya ialah Pejabat Pelaksana Pengadaan berdasarkasn SK Direksi PT PLN Nomor 305 tahun 2010 (SK sebelumnya) penawaran tersebut digugurkan atau penawaran tersebut gagal. Namun, berdasarkan SK Direksi 620 tahun 2013 yang terbaru, dilakukan negosiasi semaksimal mungkin untuk mendekati HPS atau sampai di bawah HPS. Hal ini dilakukan karena jika pengadaan gagal maka efisiensi waktu yang mana salah satu prinsip dasar pengadaan tidak tercapai.

c. Dalam hal pengajuan penawaran harga, calon penyedia barang/jasa sering mengajukan penawaran terlalu rendah yaitu dengan nilai 70 $\%$ di bawah HPS, sedangkan dalam Rencana Kerja Syarat (RKS) tidak diperbolehkan mencantumkan kriteria prosentase turunya nilai penawaran. Pemecahan masalah ini ialah jika calon penyedia barang/jasa tersebut diusulkan sebagai pemenang maka hendaknya calon penyedia barang/jasa tersebut diklarifikasi dan dipastikan kesanggupannya dan dalam kontrak ditambahkan klausul yang mengatur mengenai penyedia barang/jasa tidak mensubkan pekerjaan tersebut. Dalam mengajukan pemenang dari pengadaan barang/jasa yang dilakukan dibutuhkan pertimbangan dari Value For Money Committee, dimana Value For Money Committee berasal dari pejabat struktural yang ada di PLN Bali. Namun, bagaimana dengan pelaksanaan pengadaan barang/jasa di kantor unit dimana dalam kondisinya belum ada Value For Money Committee. Hal ini akan dibijaksanai oleh Pengguna Barang/Jasa bahwa Pejabat Pelaksana Pengadaaan membuat Pakta Integritas.

d. Adanya sistem E-Procurement yang belum mampu melingkupi semua kegiatan dari proses pengadaan. Misalnya saja saat pembagian dokumen pelelangan/RKS kepada calon penyedia masih berupa hard copy dan belum mampu untuk di upload ke sistem E-Procurement jadi dari segi efisiensi kurang terpenuhi. Pemecahan masalahnya ialah Manajemen membijaksanai dengan menyimpan dokumen tersebut dalam bentuk softcopy yang kemudian dibagikan kepada calon penyedia barang dan jasa.

e. Dalam pelaksanaannya vendor atau rekanan sering lalai dalam proses pengadaan barang dan atau jasa itu sendiri, misalnya saat pendaftaran keikutsertaan dalam E-Procurement, vendor telah mendaftarkan dirinya tetapi belum mengambil dokumen pengadaan tersebut, sehingga pada 
saat waktu yang ditentukan vendor ini tidak mau untuk digugurkan, padahal proses pengadaan ini memerlukan waktu yang sangat singkat. Kemudian, adanya calon Penyedia Barang/Jasa yang sudah tahu perusahaanya tidak memenuhi kualifikasi dan proses pengadaan yang berlangsung tidak memperkenankan adanya konsorsium tetapi tetap memaksa ikut serta dalam proses pengadaan tersebut sehingga sering menyebabkan terhambatnya proses ini. Selain itu, dalam pengadaan barang dan jasa sering kali ada persepsi dari pihak eksternal dan internal PLN Bali bahwa harga termurah dalam suatu pelelangan terbuka yang kompetitif dapat mengalahkan aspek lainnya seperti, kualitas. Sehingga sering terjadi jika calon penyedia barang/ jasa dapat menawarkan harga sangat murah dengan menurunkan kualitas barang/ jasa ataupun aspek lainnya. Solusi dalam hal seperti ini ialah Pelaksana Pengadaan memberikan teguran kemudian catatan khusus pada rekanan tersebut untuk dipertimbangkan dalam mengikuti pengadaan barang/jasa selanjutnya. Untuk penawaran harga yang terlalu murah, pejabat pelaksana pengadaan didukung oleh SK Direksi No. 620 tahun 2013 mengatur bahwa untuk mendukung pelaksanaan GCG, pemenang tidak hanya berdasarkan nilai terendah melainkan didukung oleh spesifikasi barang/jasa yang berkualitas sehingga adanya pemenuhan unsur kewajaran (fairness).
Wawancara keempat ialah dengan Ibu Ratna, yang menghadapi kendala sebagai berikut; ${ }^{14}$

a. Saat memasukkan penawaran ke dalam sistem E-Procurement, sering terjadi error sehingga menyebabkan sedikit gangguan. Pemecahan masalahnya ialah sistem akan terus diperbaharui dan dikembangkan, walaupun sering terjadi sistem error tidak akan mengurangi unsur transparency, responsibility dan independency dalam pengadaan barang dan jasa karena dalam proses memasukkan penawaran dilakukan dalam waktu yang bersamaan oleh calon penyedia yang lain.

\section{Penutup}

\subsection{Simpulan}

Dari pembahasan tentang rumusan masalah di atas, maka dapat disimpulkan bahwa:

1. Bentuk penjabaran $G C G$ dalam pengadaan barang dan jasa pada PLN Bali ialah dalam Unsur Transparency; dapat dilihat pada pemberian informasi pengumuman lelang melalui sistem E-Procurement ataupun melaui pengumuman yang ditempelkan pada papan pengumuman pengadaan PLN. Unsur Accountability dapat dilihat pada saat melakukan tender/lelang untuk mendapatkan harga yang terbaik Pejabat Pelaksana pengadaan melakukan negosiasi. Unsur Responsibility dapat dilihat dalam Seleksi berdasarkan E-procurement

Ratna (bidang administrasi PT Ristu Darma, selaku salah satu penyedia barang/jasa di PLN Bali(wawancara dilakukan di Denpasar pada Selasa, 7 Juli 2015) 
pada PLN Bali dengan persyaratan terukur mampu mengurangi kontak langsung. Unsur Fairness ; bentuknya dapat dilihat dalam menyeleksi setiap kualifikasi sesuai persyaratan tanpa intervensi pihak ketiga. Unsur Independency ; yaitu bebas dari tekanan dalam menentukan pemenang penyedia barang/jasa.

Dengan demikian, dalam pengadaan barang dan jasa pada PT PLN telah menjalankan konsep $G C G$ dalam pelaksanaannya, yang mana didukung oleh seluruh stakeholder.

2. Dari beberapa kendala yang dijabarkan dalam pembahasan di atas dapat dilihat bahwa yang terpenting dalam mengatasi kendala yang dihadapi ialah kerjasama dari para stakeholder serta adanya kebijakan dari pihak yang berwenang, dalam hal ini manajemen yang memiliki kapasitas untuk membuat keputusan dan mengupayakan segala kendala dapat diatasi serta tetap berdasarkan pada peraturan tentang pengadaan barang dan jasa yang berlaku di PLN juga prinsip - prinsip GCG di dalamnya.

\subsection{Saran}

Saran yang dapat disampaikan dalam penelitian ini ialah:

1. Penerapan $G C G$ dalam pengadaan barang atau jasa pada PLN Bali haruslah didukung oleh seluruh stakeholder, agar apa yang menjadi harapan dari penjabaran $G C G$ dalam Pengadaan Barang dan Jasa berjalan dengan optimal. Serta diperlukan adanya "reward" dan "punishment" bagi rekanan yang mematuhi dan menerapkan prinsip $G C G$ dengan baik serta rekanan yang mencoba melanggar prinsip $G C G$ tersebut khususnya pengadaan barang dan jasa.

2. Kendala-kendala yang dihadapi dalam pengadaan barang dan jasa pada PLN Baliharusdapatdiminimalisir,misalkan saja dengan terus dikembangkannya sistem E-Procurement, agar semakin mengurangi kontak langsung antara Penyedia Barang/Jasa dengan Pejabat Pelaksana pengadaan sehingga lebih transparan. Untuk kendala yang disebabkan oleh penyedia, dapat diterapkan sanksi berupa blacklist secara tegas.

\section{DAFTAR PUSTAKA}

\section{Buku}

Daniri, Mas Achmad, 2014, Lead by GCG, Gagas Bisnis Indonesia, Jakarta.

Hamzah,Fahri, 2012, Negara,BUMN, dan Kesejahteraan Rakyat, Faham Indonesia.

Indrajit, Richardus Eko dkk, 2002, E Government Strategi Pembangunan dan Pengembangan Sistem Pelayanan Publik Berbasis Teknologi, Andi, Yogyakarta.

Kurniawan,Wahyu, 2012, Corporate Governance Dalam Aspek Hukum Perusahaan, PT Pustaka Utama Grafiti, Jakarta.

Moeljono,Djokosantoso, 2005, Good Corporate Culture sebagai inti dari Good Corporate Governance, PT Elex Media Komputindo, Jakarta.

Purba, Marisi P, 2014, Pengadaan Barang dan Jasa BUMN, Graha Ilmu, Yogyakarta. 
Sjawie, Hasbullah F, 2013, Direksi Perseroan

Terbatas serta Pertanggungjawaban

Pidana Korpoorasi, Citra Aditya Bakti, Bandung,

Ramli, Samsul dan Fahrurrazi, 2014,

Swakelola Pengadaan Barang/Jasa Pemerintah, Visimedia, Jakarta.

Waluyo, Bambang, 2008, Penelitian Hukum Dalam Praktek, Sinar Grafika, Jakarta.

Wilamarta,Misahardi. 2007, Penerapan Prinsip - Prinsip Good Corporate Governance dalam Perseroan Terbatas, Center for Education and Legal Studies, Jakarta.

Peraturan Perundang - Undangan

Undang - Undang Nomor 19 Tahun 2003 tentang BUMN

Peraturan Presiden No.54 tahun 2010 tentang Pengadaan Barang/Jasa Pemerintah

Peraturan Menteri Negara BUMN No. Per - 01 /MBU/2011 tentang Penerapan Tata Kelola Perusahaan Yang Baik (Good Corporate Governance) pada Badan Usaha Milik Negara

Putusan Menteri BUMN Nomor 05 tahun 2008 jo Peraturan Menteri BUMN Nomor 15 tahun 2012 tentang Pedoman Umum Pengadaan Barang dan Jasa Badan Usaha Milik Negara

Surat Keputusan Direksi PT PLN (Persero) Nomor 620 tentang Pedoman Pelaksanaan Pengadaan Barang dan Jasa di lingkungan PT PLN (Persero)
Jabatan : Pejabat Perencana Pengadaan

2. Nama : Ketut Mindiawan

TTL : Buduk, 31 Desember 1959

Alamat : Buduk, Mengwi

Jabatan : Pejabat Pelaksana Pengadaan

3. Nama : I Gde Arie Widyantara P.

TTL : Amlapura, 23 Maret 1985

Alamat : Jln Nusa Indah, Dps

Jabatan : Supervisor Pelaksana Pengadaan

4. Nama : Ratna TTL : Banyuwangi, 21 April 1974

Alamat : Br.Umadesa Peguyangan

Jabatan : Bidang Administrasi pada PT Ristu Darma

\section{Biodata :}

Nama : Luh Putu Dwi Suarini, SH

Alamat : Jalan Sedap Malam III No.9 Denpasar

No. HP : 081236236469

\section{Data Informan}

1. Nama : I Gede Ketut Anom

TTL : Tabanan,14 Agustus 1959

Alamat : Denpasar 